\title{
Schattenseiten der Globalisierung
}

Liebe Leserin, lieber Leser,

Covid-19 hat direkte Folgen für die Weltwirtschaft, kann aber auch als Schuss vor den Bug angesehen werden. Denn es zeigt sich, dass unsere Systeme nicht dazu ausgelegt sind, längerfristig autark zu funktionieren. Zu allem Überfluss sind unsere Lieferketten $\mathrm{zu}$ einseitig und deutlich zu lang. Wenn wir eine Lehre aus der Situation ziehen wollen, dann die, dass wir unsere Abhängigkeiten verteilen sollten. Fällt dann ein Produktionsstandort aus, können wir auf andere zurückgreifen. Zugegeben, vermutlich werden die Produkte dadurch etwas teurer, Produktionsstopps aber kosten deutlich mehr.

Das gleiche Prinzip sollten wir auch dringend anwenden, wenn wir neue Wege beschreiten wollen - wie bei der dezentralen Stromerzeugung und der Versorgung mit regenerativ erzeugter Energie sowie dem Aufbau von Anlagen zur Herstellung alternativer Kraftstoffe. Es scheint einen Konsens darüber zu geben, dass die Erzeugung von Strom durch Solaranlagen an Sweet Spots in Nordafrika und Australien zielführend ist und die Energie dort in Form von transportfähigen gasförmigen oder flüssigen chemischen Energieträger zu speichern. Es wäre ein Fehler, die Anlagen zu zentralisieren oder verschiedene Verfahren in einzelnen Regionen exklusiv anzuwenden. Denn dadurch ergäben sich neue Abhängigkeiten, wie wir sie bereits bei der Versorgung mit Rohöl aus dem Mittleren Osten kennen. Umso größer sind Chancen und Nutzen, wenn viele verschiedene Länder alle Möglichkeiten von Stromerzeugung über Elektrolyse bis hin zur Kraftstoffproduktion erhalten.
Dem zeitnahen Markthochlauf von synthetischen Kraftstoffen und der Technologieoffenheit steht entgegen, dass sich Volkswagen mittelfristig aus der Produktion von Fahrzeugen mit CNG-Antrieb zurückziehen will - und das, obwohl der Konzern noch 2019 eine Produktoffensive angekündigt hat. Zugegeben: Die Technologie verkauft sich schleppend, auch die politischen Entscheider verschlafen eine Möglichkeit, erhebliche Mengen $\mathrm{CO}_{2}$ einfach und effektiv einzusparen.

Wenn uns dieses Vorgehen nicht in ein paar Jahren auf die Füße fällt - so wie es augenblicklich unsere zu langen Lieferketten tun.

Ich wünsche viel Vergnügen bei der Lektüre dieser MTZ

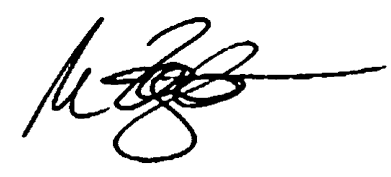

Marc Ziegler

Stellvertretender Chefredakteur

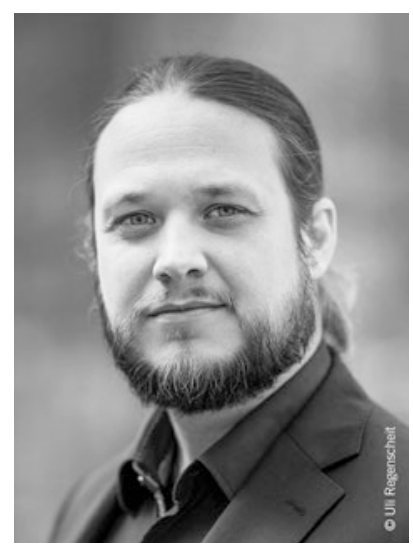

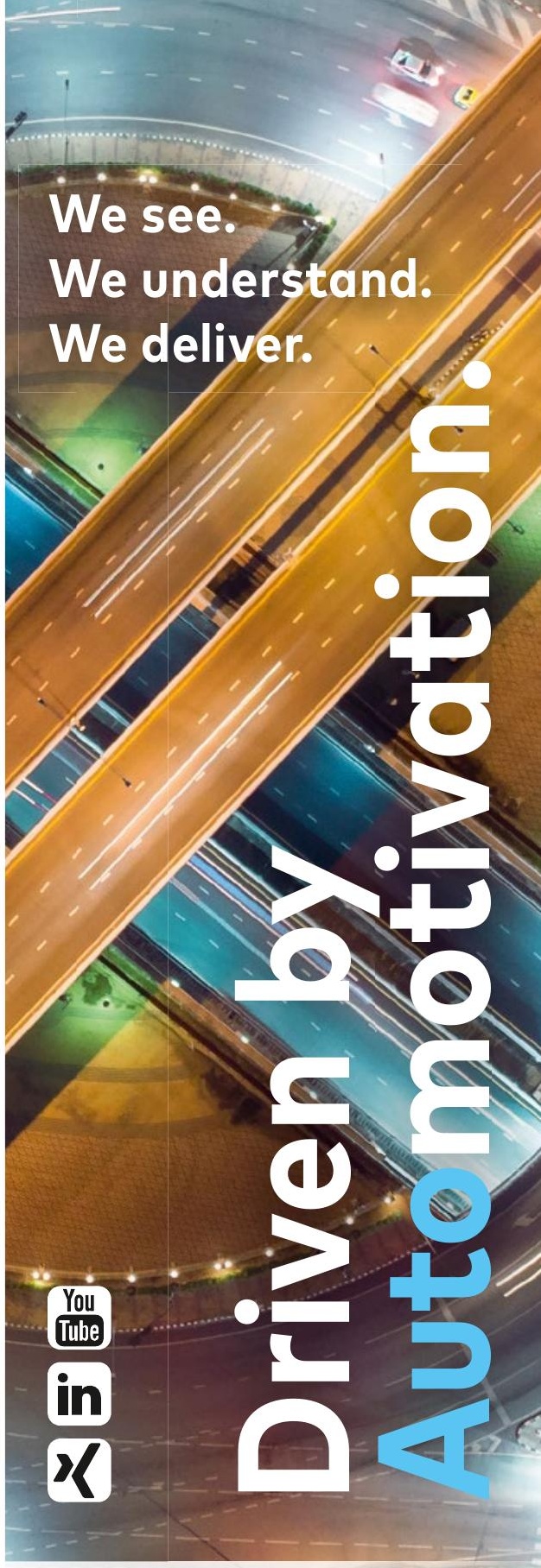

Family owned. $100 \%$ committed. 